\title{
Taiwan to boost biomedical research
}

Taipei. Taiwan is creating a new medical research organization that will be run along similar lines to Britain's Medical Research Council and the US National Institutes of Health. It will be staffed largely by Chinese medical researchers drawn back from the United States.

Cheng-Wen $\mathrm{Wu}$, director of the Institute of Biomedical Sciences of Academia Sinica in Taipei, is leading the creation of the new organization called the National Health $\mathrm{Re}$ search Institutes (NHRI). He has already looked at several potential sites for NHRI, which will run an extramural grant programme and carry out intramural research.

$\mathrm{Wu}$ says the government is giving full backing to the organization, which will have between 500 and 1,000 researchers in its first five years of operation, because of the success of his own institute. Since its establishment six years ago, this has grown into the largest research institute in Academia Sinica with 400 staff, including more

than 300 scientists.

But some other institutes in the academy are uncomfortable with such rapid growth. Thus although Wu's institute will take a leading role in helping to establish the new organization, NHRI will be independent of Academia Sinica.

It will be an autonomous non-profit organization run by a board of trustees that will include the chairman of the National Science Council (NSC), the president of Academia Sinica, and the ministers of health and education, as well as medical researchers from Taiwan and overseas.

The NHRI plans to have multiple sources of funds, but the health ministry will be the biggest provider. An extramural grant programme started this July with 40 centres of excellence in hospitals and universities each receiving up to NT\$50 million (\$1.8 million) a year, and 20 outstanding investigators up to NT\$5 million each.

Unlike other grant programmes in Tai-

\section{Chemist tipped for top academy post}

Taipei. A group of $\mathbf{5 0}$ leading Taiwanese academics will meet in Taipei on Saturday (11 December) to select three candidates for the presidency of Academia Sinica, Taiwan's leading organization for government research.

This is a rare event, because presidents are appointed for life. The most likely candidate for the post is Nobel prize-winning chemist Yuan Lee of the University of California at

Berkeley. Another possible candidate is Ying-shih Yu, a professor of Chinese history at Princeton University.

The final

\section{IMAGE \\ UNAVAILABLE FOR COPYRIGHT} REASONS

choice will be made from three Individuals nominated by the academy to the presi-

Lee: Ilkely candidate.

dent of Taiwan, T. H. Lee. The academy president will have to oversee 21 Institutes in science and the humanities, with an annual combined budget that has increased ten-fold over the past decade to US\$110 million, but which is now being squeezed by other government priorities.

Wu Tayu, an 87-year-old physicist who has been president for the past ten years, decided to retire after harsh questioning over the budget for the academy by opposition members In the legislature earlier this year. Academy officials deny reports that Wu's retirement is directly related to his fallure to persuade Talwan to contrib- ute to the US Superconducting Super Collider (SSC) project. But others feel it may have been a factor.

The academy has experienced rapid growth over the past decade. Seven new institutes have been founded - for Earth science, information science, statistical science, atomic and molecular science, molecular biology, biomedical science and computing - and the number of researchers has doubled, to about $\mathbf{9 0 0}$.

But the academy's budget has been squeezed in the past year as the government embarks on an ambitious six-year plan to improve roads and other infrastructure. The new president will have a difficult task on his hands because there is a perception in government circles that too much effort is put into basic research and producing publications and not enough on practical research of immediate use to society.

The $\mathbf{5 0}$ members of the academy's council, which includes approximately equal numbers from the three areas of mathematics and physical sciences, life science, and humanities and social science made up of the heads of the academy institutes and members from overseas, will nominate three candidates, usually one from each of the three main fields.

Yuan Lee is the most frequently mentioned potential candidate. He is one of the members of the councll, and has already decided to return to Taiwan in January, whether or not he is elected president, to work as a 'distinguished fellow' in the new Institute of Atomic and Molecular Sciences. wan, which have an approval rate for applications of about 80 per cent, the NHRI programme makes use of a thorough peer review process, including referees from the United States, and only about 20 per cent of applications are funded. Wu expects the extramural programme to have a budget of about NT $\$ 500$ million (US\$18.5 million) in its first few years of operation.

Eventually $\mathrm{Wu}$ wants to build several institutes on a site of 50 to 100 acres. But the intramural programme will start next July, before the establishment of any institutes, with funds of about NT\$300 million for six research groups: ageing research; environmental toxicology and occupational disease; health care policy; biotechnology and pharmaceuticals (including clinical trials); medical engineering; and Chinese traditional medicine. Once a sufficient 'critical mass' of researchers is gathered, various institutes will be established.

The new organization will recruit most of its researchers from the United States. $\mathrm{Wu}$, who returned from the United States six years ago, but only recently gave up a post at the State University of New York, Stony Brook, is one of the founding members of the 2,000-strong Society of Chinese Bioscientists in the United States. He reckons there are about 5,000 Chinese bioscientists in the United States and he says people are already lining up at his door.

Some Taiwanese biologists, however, are concerned that the new organization will be a drain on limited resources, and that basic research in biology and medicine will suffer. The government last year started a US\$190-billion six-year national programme for the improvement of infrastructure and roads that has cut into budgets for science.

David Swinbanks

\section{WHO plans guidelines for genetics research}

Paris. Hiroshi Nakajima, director general of the World Health Organization(WHO), last week proposed that the organization establish a set of international guidelines for research in genetics and biotechnology, as well as for its social applications.

Giuseppe Benagiano, director of the WHO's Special Programme of Research, Development and Research Training in Human Reproduction, says all laboratories funded by the WHO are likely to be required to observe the guidelines. He adds that the WHO's reputation should ensure that most laboratories outside its jurisdiction also observe them.

The WHO's executive board will decide in January whether to go ahead with the plan, which would start with a broad consultation with the scientific community. D. B. 